\title{
La importancia del padre en Psicoanálisis
}

\author{
Lic. Daniel A. Fernández ${ }^{1}$
}

Para hablar de la función paterna, al menos desde una visión psicoanalítica, es preciso recordar brevemente que el Complejo de Edipo tiene un papel central. A partir del Edipo se da entrada en la cultura, en la exogamia y se da la característica viril o femenina del sujeto. Y hacemos este recordatorio porque, precisamente, es en el Edipo donde resulta esencial la función del padre. De hecho, podríamos decir que no hay Edipo sin padre o sin alguien que cumpla su función.

Podemos decir que el padre interviene sobre varios planos, pero ante todo él habrá de prohibir a la madre. La relación entre el niño y el padre está comandada por el temor a la castración. Y es en tanto que el padre es amado, que el sujeto se identifica con él y llega a su término el Edipo.

Lacan (1957/1994) sugiere que toda la cuestión es saber lo que el padre es en el Complejo de Edipo. Para esto es que él habla de la "Metáfora paterna". Y si partimos de la base que en una metáfora siempre viene una cosa a sustituir a otra cosa, podemos decir que el Complejo de Edipo tiene la estructura de una metáfora y que, en ésta, viene el nombre del padre a sustituir el deseo por la madre. La función del padre en el Complejo de Edipo, entonces, es precisamente ser un significante que sustituye a un significante anterior. Dicho de una manera más clara: separar al hijo de su madre como objeto incestuoso. Es decir que la metáfora paterna introduce una legalidad psíquica, un orden.

También se debe tener en cuenta que, en un primer momento, el niño viene para la madre a ocupar el lugar de falo, es decir de lo que a ella le falta y desea (ecuación niño-falo mediante). Flesler A. (2004) manifiesta que creer ser el falo de la madre es un tiempo esencial, porque de eso depende la constitución del narcisismo (momento evolutivo imprescindible) y la constitución de la imagen corporal. Y es así cómo debe

\footnotetext{
${ }^{1}$ Universidad Argentina John F. Kennedy. Correo electrónico: danielfernandez@ flashmail.com
} 
desarrollarse la primera vinculación entre la madre y el hijo. Pero si bien, en un primer momento, el niño debe ser el falo de la madre, también es cierto que en un momento posterior debe dejar de serlo. Y aquí también interviene la función del padre, dado que es él quien castra a la madre de ese hijo que tiene como falo.

En síntesis, diremos que la función del padre en el Edipo será fundamentalmente la de separar a la madre del hijo, de tal modo que: por un lado el niño deje de tomar a esa madre como objeto de deseo incestuoso y, por otro lado, que la madre deje de tomar a ese hijo como falo (que no lo sea todo para la madre).

Es importante destacar que la amenaza de castración juega un papel tan relevante, que la reacción del niño ante ésta va a determinar su futura estructura psíquica. Y si estudiamos a Berenstein (1991), veremos que este autor amplía la función paterna y dice que incluso el padre debe operar cierta separación entre su esposa y la familia de origen de ésta. Esta última separación habrá de ser fundamental -según el autor mencionado-, pues de que dicha separación se haga efectiva dependerá en gran parte la salud mental de los hijos de la nueva pareja.

Por otra parte, Aberastury (1974) observa que el ejercicio de la paternidad es importante a lo largo de toda la vida del sujeto, pero da cuentas de cómo la presencia del padre es especialmente importante en los siguientes momentos:

- A partir del nacimiento: El padre, al igual que la madre, deberán participar de los cuidados del hijo desde un comienzo. Los progenitores deben presentar un modelo de identificación para el niño o niña. Estos requieren de modelos sexuales, y por ello serán necesarias las dos figuras (masculina y femenina). En estudios sobre homosexuales, se detectó que éstos no habían tenido contacto o interacción profunda con sus padres. 
- Durante el primer año de vida: El padre deberá elaborar su propia posición femenina. Aberastury propone que éste también se ocupe de tareas tradicionalmente asignadas a las madres, como por ejemplo la de cambiar los pañales al niño. Winnicott (1971) decía, justamente, que el varón no tenía que haber roto con la mujer y el niño que llevaba dentro.

- Durante el segundo año de vida: Aquí el padre debe intervenir procurando disolver los resabios de simbiosis con la madre que aún pudieran existir. El padre debe proponer juegos y resolver la relación diádica con la madre.

- En la etapa escolar: Aquí se destaca la importancia de la presencia del padre en lo que refiere a temas relacionados con la escuela del niño. El padre deberá acompañar a sus hijos en el aprendizaje, mostrándose interesado en las tareas que el niño lleva a cabo en la escuela.

- En la adolescencia: En esta etapa, de parte del padre, debe haber tolerancia a los cuestionamientos. El padre deberá mostrar presencia y acompañar al hijo. El crecimiento del hijo supone la caída del padre, y esto genera una crisis que el padre deberá aprender a tolerar.

De lo hasta aquí expuesto, se deduce con claridad que la función del padre no se reduce a una función de corte dentro de la conflictiva edípica, sino que es además dador de emblemas de identificación y tiene un papel relevante en las distintas etapas evolutivas del hijo. 


\section{BIBLIOGRAFÍA}

Aberastury, A. \& Knobel, M. (1974). La adolescencia normal. Buenos Aires: Editorial Paidós.

American Psychological Association. (2001). Publication manual of the American Pshychological Association ( $5^{\text {th }}$ ed.). Washington, DC: Author.

Berenstein, I. (1991). Familia e inconsciente. Buenos Aires: Editorial Paidós.

Flesler, A. (2004). Seminario: Las intervenciones del analista en el análisis de un niño. Clase 2. Buenos Aires: Escuela Freudiana de Buenos Aires.

Lacan, J. (1994). Del complejo de castración. En El seminario de Jacques Lacan, Libro 4: La relación de objeto. Texto establecido por Jacques-Alain Miller. Buenos Aires: Editorial Paidós. (Trabajo original de 1957).

Winnicott, D. (1971). Escritos de pediatría y psicoanálisis (1931-1956). España: Editorial Laia.

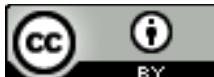

Este texto está protegido por una licencia Creative Commons 4.0.

Usted es libre para Compartir — copiar y redistribuir el material en cualquier medio o formato - y Adaptar el documen- to - remezclar, transformar y crear a partir del material- para cualquier propósito, incluso comercialmente, siempre que cumpla la condición de:

Atribución: Usted debe reconocer el crédito de una obra de manera adecuada, proporcionar un enlace a la licencia, e in- dicar si se han realizado cambios. Puede hacerlo en cualquier forma razonable, pero no de forma tal que sugiera que tie- ne el apoyo del licenciante o lo recibe por el uso que hace. 